\title{
Closure of bronchopleural fistula using a dumbbell-shaped closure device
}

Huihuang Lin, MD, Yiming Zeng, MD, Yixiang Zhang, MD, and Huaping Zhang, MD, Quanzhou, China

\footnotetext{
From the Department of Pulmonary Disease, The Second Affiliated Hospital of Fujian Medical University, Quanzhou, China.

Disclosures: Authors have nothing to disclose with regard to commercial support.

Received for publication March 18, 2016; revisions received June 22, 2016; accepted for publication June 26, 2016; available ahead of print Aug 16, 2016.

Address for reprints: Yiming Zeng, MD, Department of Pulmonary Disease, The Second Affiliated Hospital of Fujian Medical University, Quanzhou, China, 34 North Zhongshan Rd, Quanzhou, 362000 Fujian Province, China (E-mail: zeng_yi_ming@aliyun.com).

J Thorac Cardiovasc Surg 2016;152:e119-21

$0022-5223 / \$ 36.00$

Copyright (C) 2016 by The American Association for Thoracic Surgery

http://dx.doi.org/10.1016/j.jtcvs.2016.06.060
}

Bronchopleural fistula (BPF) is defined as a communication between a lobar or segmental pulmonary bronchus and the pleural space. Although the incidence of BPF has declined in recent years, ${ }^{1}$ it remains a major challenge and is associated with a high rate of mortality. In this article, we describe a novel technique involving the use of a dumbbell-shaped closure device for the closure of BPF.

\section{CASE REPORT}

A 53-year-old man underwent a right pneumonectomy (T3N0M0) for right lower-lobe adenocarcinoma and received postoperative chemotherapy. After 3 months of treatment, he experienced fever, cough, sputum, and dyspnea. A bronchoscopy revealed a fistula in the right main bronchial stump (Figure 1, A). Computed tomography of the chest showed a 4-mm BPF between the bronchial stump and the pleural space. We inserted a chest tube, and purulent fluid was drained continuously every day. A diagnosis of right main BPF with empyema was established. The patient refused another surgery for closure of the BPF. After antibiotic therapy and chest tube drainage was performed, we decided to use a specially designed dumbbell-shaped closure device to exclude the right stump.

The dumbbell-shaped closure device was a selfexpandable nitinol device, which consisted of 3 parts (the distal portion, the proximal portion, and the connecting bar) (Figure 1, $B$ and $C$ ). To exclude the fistula, the distal portion and proximal portion were both sphere-shaped and covered with polyethylene. The connecting bar was uncovered to prevent migration of the device. According to our specifications, a local manufacturer (Micro-Tech, Nanjing, P R China) constructed the device.

The procedure of the device placement was performed by a bronchoscope with the patient under topical anesthesia. After local anesthesia with $2 \%$ lidocaine, the

\section{DISCUSSION}

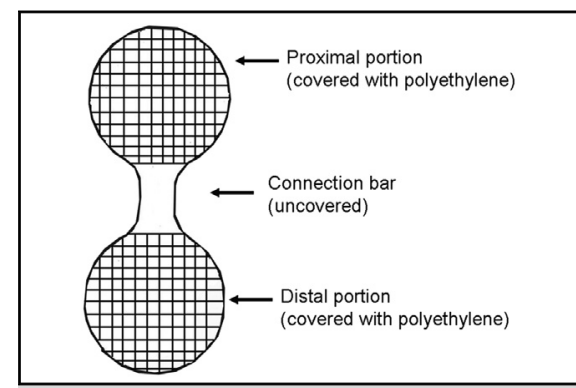

The dumbbell-shaped closure device consisted of 3 parts.

\section{Central Message}

We describe a novel technique involving the use of a dumbbell-shaped tracheobronchial closure device for the closure of bronchopleural fistula.

See Editorial Commentary page e121.

bronchoscope was introduced in the right bronchial stump. A guidewire was passed through the working channel of the bronchoscope into the fistula. A 16-F introducer deliver system with the closure device was passed over the guidewire into the bronchus. Then, the closure device was released successfully by pulling back the introducer sheath under bronchoscopic vision. The proximal portion on the bronchial side and the distal portion in the pleural space were both deployed successfully. After the placement of the device, the patient showed immediate improvement of the symptoms, and the discharge from the chest tube was reduced significantly (Figure 2). Two months later, followup bronchoscopy revealed that the BPF was completely sealed off with granulation tissue developing around the connecting bar of the device (Figure 1,D). The patient died 6 months later as the result of cancer recurrence.

BPF represents a severe complication after pulmonary resection, with the incidences ranging from $1.5 \%$ to $28 \%^{2}$ and mortality rates varying from $25 \%$ to $71.2 \%$. $^{3}$ Currently, the treatment of the patients with BPF includes surgical and bronchoscopic treatment. When a patient refuses surgery or is not a surgical candidate, bronchoscopic treatment of BPF appears to be an efficient alternative.

Various endoscopic treatments have been reported in the literature for the closure of BPF. Lois and Noppen ${ }^{2}$ described 


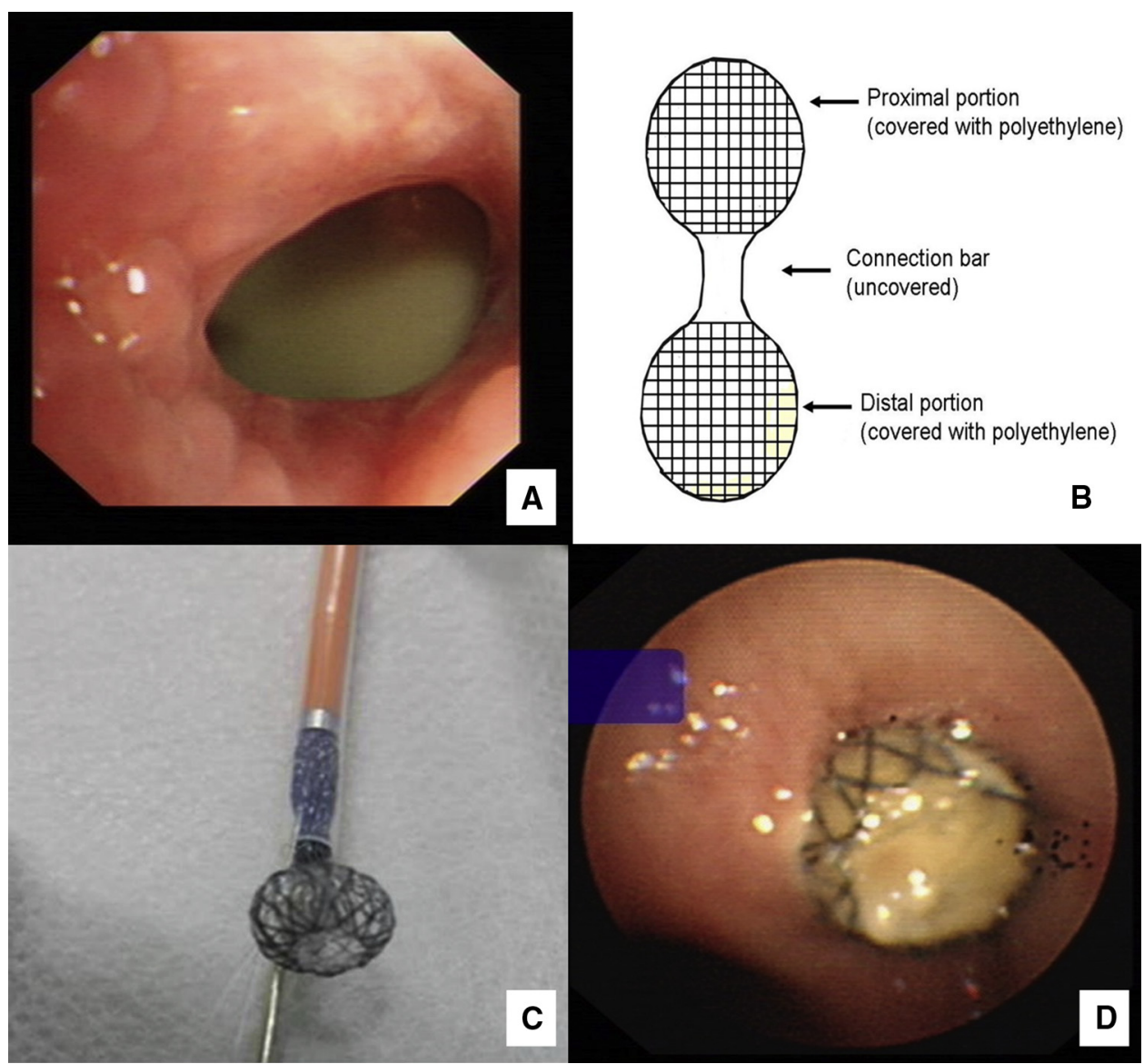

FIGURE 1. Images from a 53-year-old man who underwent right pneumonectomy as a result of lung cancer. A, Bronchoscopy showed a fistula in the right main bronchial stump. B and C, The dumbbell-shaped closure device which we used in the case. D, Two months later, follow-up bronchoscopy revealed that the BPF was completely sealed off with granulation tissue developing around the closure device.

the different methods: lead shots, ethanol, polyethylene glycol, cyanoacrylate glue, blood clot, cellulose, gel foam, and others. The use of closure devices also has been reported in

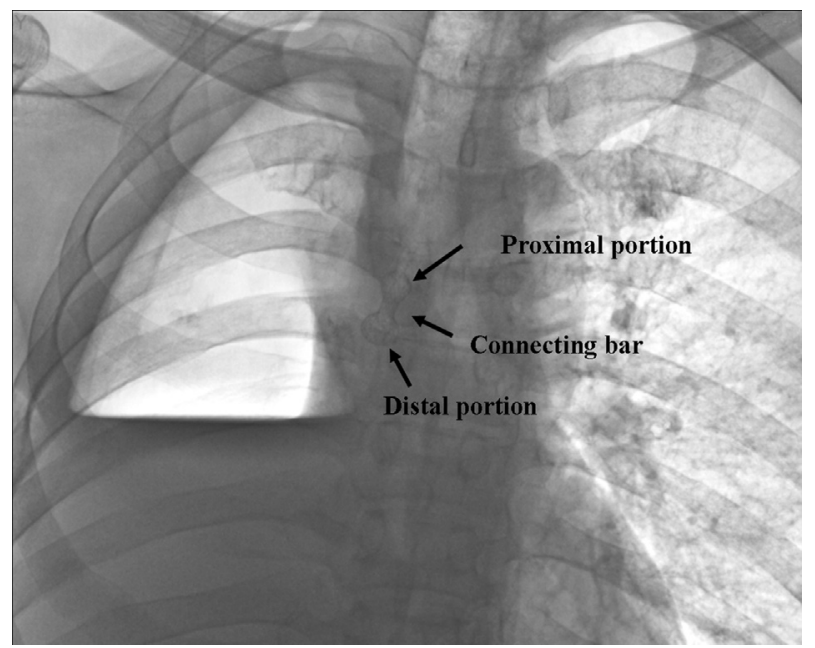

FIGURE 2. Chest $x$-ray after closure device placement. The dumbbellshaped closure device in site is clearly visible. the management of postpneumonectomy BPF. Because there are no closure devices specifically designed for the treatment of BPF, factors such as the feature of the fistula, the physical characteristics of the closure device, and its possible complications should be considered in the selection of a closure device.

In this report, we used a custom-made closure device to treat postpneumonectomy BPF. Our device was somewhat similar to an atrial septal defect occluder. ${ }^{4}$ Currently, the atrial septal defect occluder has not been approved for the treatment of BPF in China. Therefore, we designed a dumbbell-shaped closure device for closure of the fistula. The covered distal and proximal portion occludes the fistula, whereas the connecting bar prevents device migration. The closure device has the following advantages: (1) the uncovered portion enhances friction against the BPF wall, which develops granulation tissue around the device to seal BPF; (2) the covered parts can prevent aspiration to the lung or air-leak develops; (3) the dumbbell-shaped design plays an important role in fixing the device to prevent device migration; and (4) the device 
does not affect mucociliary clearance and thereby does not foster sputum retention.

\section{CONCLUSIONS}

We presented a case of postpneumonectomy BPF closed with a dumbbell-shaped closure device. We conclude that this technique might be a promising option for treating patients who are poor surgical candidates with postoperative BPF.

\section{References}

1. Hubaut JJ, Baron O, Al Habash O, Despins P, Duveau D, Michaud JL. Closure of the bronchial stump by manual suture and incidence of bronchopleural fistula in a series of 209 pneumonectomies for lung cancer. Eur J Cardiothorac Surg. 1999; $16: 418-23$.

2. Lois M, Noppen M. Bronchopleural fistulas: an overview of the problem with special focus on endoscopic management. Chest. 2005;128:3955-65.

3. Sirbu H, Busch T, Aleksic I, Schreiner W, Oster O, Dalichau H. Bronchopleural fistula in the surgery of non-small cell lung cancer: incidence, risk factors, and management. Ann Thorac Cardiovasc Surg. 2001;7:330-6.

4. Goblin JM, Prakash UB, Blanco RE. A 57-year-old man with end-stage renal disease and chronic cough. Chest. 2008;133:1021-4.

\title{
EDITORIAL COMMENTARY
}

\section{Minimally invasive closure of bronchopleural fistulae with novel closure devices: Fantasy or reality?}

\author{
Robert B. Cameron, MD \\ From the Division of Thoracic Surgery, Department of Surgery, David Geffen School of Medicine at UCLA; and \\ the Division of Thoracic Surgery, Department of Surgery and Perioperative Care, West Los Angeles VA Med- \\ ical Center, Los Angeles, Calif. \\ Disclosures: Author has nothing to disclose with regard to commercial support. \\ Received for publication July 10, 2016; accepted for publication July 12, 2016; available ahead of print Aug 24, \\ 2016. \\ Address for reprints: Robert B. Cameron, MD, Division of Thoracic Surgery, Department of Surgery, David Gef- \\ fen School of Medicine, 10780 Santa Monica Blvd, Suite 100, Los Angeles, CA 90025 (E-mail: rcameron@ \\ stanfordalumni.org). \\ J Thorac Cardiovasc Surg 2016;152:e121-2 \\ $0022-5223 / \$ 36.00$ \\ Copyright $\odot 2016$ by The American Association for Thoracic Surgery \\ http://dx.doi.org/10.1016/j.jtcvs.2016.07.026
}

Bronchopleural fistulae (BPFs), particularly in patients who have undergone pneumonectomy, remain a substantial, albeit infrequent, thorn in the side of thoracic surgeons. Closure of these fistulae typically requires multiple operations, including open Eloesser-style drainage procedures and subsequent procedures designed to close the bronchial defect and to either obliterate the remaining space with muscle flaps or reduce it with thoracoplasty-operations for which some patients may not be candidates or willing participants. Transpericardial closure of postpneumonectomy fistulae may be helpful, as described by Padhi and Lynn $^{1}$ using an anterior thoracotomy approach or as described by Ginsberg and colleagues ${ }^{2}$ via a transsternal approach originally suggested by Mikhail Perelman. ${ }^{3}$ However, both approaches still require major operations and an adequate length of residual bronchus, which may be absent in many patients undergoing pneumonectomy.

Endobronchial methods to close fistulae have been imaginatively explored for years with minimal success. A

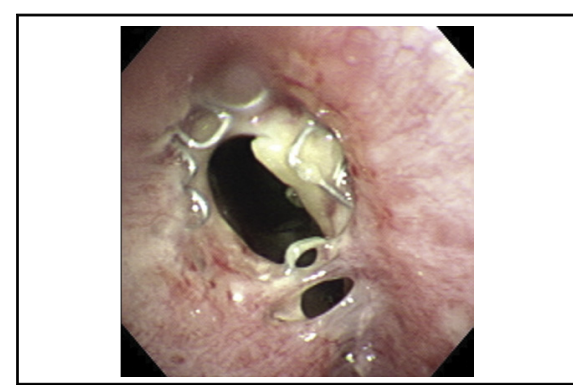

Bronchopleural fistula demonstrating staples eroding through the bronchial wall.

\section{Central Message}

Novel closure devices may help reduce the morbidity and mortality from bronchopleural fistulae, particularly in patients undergoing pneumonectomy, but prevention remains key.

See Article page e119.

laundry list of materials and devices have been tried, including lead shots, glues (cyanoacrylate), bioglues, Gelfoam (Pfizer, New York, NY), various modified stents, and endobronchial valves. ${ }^{4-10}$ After the introduction of patent foramen ovale and atrial septal defect closure devices, such as the Amplatzer (St. Jude Medical, St. Paul, Minn) and Occlutech Figulla (Occlutech, Helsingborg, Sweden), reports began surfacing that use these or similar individually constructed devices in the transbronchial closure of BPFs. ${ }^{9-11}$ For instance, Fruchter 